\title{
Neurological outcomes and surgical complications in 221 spinal nerve sheath tumors
}

\author{
Michael M. Safaee, MD, ${ }^{1}$ Russ Lyon, MS, DABNM, ${ }^{1}$ Nicholas M. Barbaro, MD, ${ }^{2}$ Dean Chou, MD, ${ }^{1}$ \\ Praveen V. Mummaneni, MD, ${ }^{1}$ Philip R. Weinstein, MD, ${ }^{1}$ Cynthia T. Chin, MD, ${ }^{3}$ \\ Tarik Tihan, MD, PhD, ${ }^{4}$ and Christopher P. Ames, MD ${ }^{1,5}$
}

Departments of ${ }^{1}$ Neurological Surgery, ${ }^{3}$ Radiology, and ${ }^{5}$ Orthopedic Surgery; and ${ }^{4}$ Department of Pathology, Neuropathology Unit, University of California, San Francisco, California; and 'Department of Neurological Surgery, Indiana University, Indianapolis, Indiana

OBJECTIVE Among all primary spinal neoplasms, approximately two-thirds are intradural extramedullary lesions; nerve sheath tumors, mainly neurofibromas and schwannomas, comprise approximately half of them. Given the rarity of these lesions, reports of surgical complications are limited. The aim of this study was to identify the rates of new or worsening neurological deficits and surgical complications associated with the resection of spinal nerve sheath tumors and the potential factors related to these outcomes.

METHODS Patients were identified through a search of an institutional neuropathology database and a separate review of current procedural terminology (CPT) codes. Age, sex, clinical presentation, presence of neurofibromatosis (NF), tumor type, tumor location, extent of resection characterized as gross total or subtotal, use of intraoperative neuromonitoring, surgical complications, presence of neurological deficit, and clinical follow-up were recorded.

RESULTS Two hundred twenty-one tumors in 199 patients with a mean age of 45 years were identified. Fifty-three tumors were neurofibromas; 163, schwannomas; and 5, malignant peripheral nerve sheath tumors (MPNSTs). There were 70 complications in 221 cases, a rate of $32 \%$, which included 34 new or worsening sensory symptoms (15\%), 12 new or worsening motor deficits (5\%), 10 CSF leaks or pseudomeningoceles (4\%), 11 wound infections (5\%), 5 cases of spinal deformity ( $2 \%$ ), and 6 others ( 2 spinal epidural hematomas, 1 nonoperative cranial subdural hematoma, 1 deep venous thrombosis, 1 case of urinary retention, and 1 recurrent laryngeal nerve injury). Complications were more common in cervical (36\%) and lumbosacral (38\%) tumors than in thoracic (18\%) lesions ( $p=0.021)$. Intradural and dumbbell lesions were associated with higher rates of CSF leakage, pseudomeningocele, and wound infection. Complications were present in 18 neurofibromas (34\%), 50 schwannomas (31\%), and 2 MPNSTs (40\%); the differences in frequency were not significant $(p=0.834)$. Higher complication rates were observed in patients with NF than in patients without $(38 \%$ vs $30 \%$, $p=0.189)$, although rates were higher in NF Type 2 than in Type 1 (64\% vs 31\%). There was no difference in the use of intraoperative neuromonitoring when comparing cases with surgical complications and those without $(67 \%$ vs $69 \%, p=$ $0.797)$. However, the use of neuromonitoring was associated with a significantly higher rate of gross-total resection $(79 \%$ vs $66 \%, p=0.022$ ).

CONCLUSIONS Resection is a safe and effective treatment for spinal nerve sheath tumors. Approximately $30 \%$ of patients developed a postoperative complication, most commonly new or worsening sensory deficits. This rate probably represents an inevitable complication of nerve sheath tumor surgery given the intimacy of these lesions with functional neural elements.

http://thejns.org/doi/abs/10.3171/2016.5.SPINE15974

KEY WORDS nerve sheath tumor; spine; neurofibroma; schwannoma; oncology

$\mathrm{P}$ RIMARY spinal column tumors arising from the neural elements are relatively rare lesions representing approximately $5 \%$ of adult primary central nervous system tumors. ${ }^{2,7,10}$ They can occur in a variety of anatomical locations including intramedullary, intradural extramedullary, dumbbell (intradural, both intraspinal and extraspinal), and extradural. Intramedullary tumors are primarily glial (ependymomas and astrocytomas), while extradural lesions consist of metastases, hematopoietic tumors, and primary bony tumors. Intradural extramedullary spinal cord tumors consist primarily of peripheral nerve sheath tumors (PNSTs) and meningiomas. ${ }^{16}$ Other entities

ABBREVIATIONS DVT = deep venous thrombosis; EMG = electromyography; GTR = gross-total resection; MEP = motor evoked potential; MPNST = malignant PNST; NF1, NF2 = neurofibromatosis Type 1, Type 2; PNST = peripheral nerve sheath tumor; SSEP = somatosensory evoked potential; STR = subtotal resection.

SUBMITTED August 14, 2015. ACCEPTED May 12, 2016.

INCLUDE WHEN CITING Published online July 29, 2016; DOI: 10.3171/2016.5.SPINE15974. 
include lipomas, spinal nerve sheath myxomas, paragangliomas, sarcomas, and vascular tumors. ${ }^{1}$

Spinal neurofibromas are found in up to $38 \%$ of patients with neurofibromatosis Type 1 (NF1), ${ }^{9,19,26,27}$ one of the most common autosomal dominant disorders, affecting 1 in 3500 individuals, with significant heterogeneity in its clinical manifestation. ${ }^{30}$ Spinal neurofibromas reportedly cause symptoms in approximately 5\% of these patients; however, this estimate is probably too low..$^{12,27,29}$ Familial spinal neurofibromatosis is an alternate form of neurofibromatosis that is categorized by multiple neurofibromas symmetrically affecting the entire axial spine. ${ }^{5,20,28}$ Spinal schwannomas are relatively rare with an incidence of $0.3-0.4$ cases per 100,000 persons per year, and patients with these tumors generally present in the 4th or 5th decades of life. ${ }^{24}$ An estimated $90 \%$ of schwannomas are sporadic and solitary lesions, $4 \%$ arise in the setting of NF Type 2 (NF2), and another 5\% occur in multiples but are unassociated with NF2. ${ }^{4}$ Neurofibromatosis Type 2 has an estimated incidence of 1 case in 25,000-40,000 persons and has the hallmark imaging finding of bilateral vestibular schwannomas. ${ }^{17}$ A newer diagnosis of schwannomatosis has been described and by definition includes the phenotypic hallmark of multiple schwannomas without the involvement of cranial nerve VIII. Its prevalence is unknown, but its reported incidence ranges from 1 case in 40,000-700,000 persons, with most authors suggesting an incidence similar to that of NF2 ${ }^{17}$ Malignant PNSTs have a worse prognosis than neurofibromas and schwannomas with an incidence of 1 case in 10,000 persons, but they are more common in patients with NF1, where over half of these tumors are found..$^{25}$

Spinal nerve sheath tumors are rare entities, and published studies are limited to single-institution case series. $3,6,8,11,14,22-24$ Studies focusing purely on surgical complications are limited. Among the studies in which surgical complications are defined as events such as wound infections, CSF leaks, deep venous thrombosis (DVT), or pulmonary complications, those by Fernandes et al. ${ }^{11}$ and Seppälä et al. ${ }^{23}$ cite rates of around $10 \%$, whereas Nanda et al. ${ }^{18}$ cite rates up to $30 \%$; however, this latter study includes recurrence as a type of complication. When examining neurological outcomes such as new or worsening motor and sensory deficits, rates range from $5 \%$ to $30 \% .6,14,15,22-24$ The goal of the present study was to identify the rates of new or worsening neurological deficits and surgical complications associated with the resection of spinal nerve sheath tumors treated at our institution and the potential factors related to these outcomes.

\section{Methods}

The Committee on Human Research, our institutional review board, approved all research activities.

\section{Data Collection}

Two authors (N.M.B. and C.P.A.) identified patients through a search of our institutional neuropathology database and a separate review of current procedural terminology (CPT) codes. These databases included 25 years of patient records (1991-present); however, most identified patients had been treated over the past decade (2006-2016). In total, 5 surgeons contributed cases to this series: N.M.B, D.C., P.V.M., P.R.W., and C.P.A. Pathology records were reviewed to include the following PNSTs: neurofibromas, schwannomas, and malignant PNSTs (MPNSTs). Medical records were reviewed to include patient age at surgery and patient sex, presence of NF1 or NF2 according to clinical criteria, presenting symptoms and their duration, tumor location, tumor size (defined by spinal levels spanned by the tumor and its maximum diameter [cm] on MRI when available), extent of resection (defined by postoperative MRI or operative report), use of spinal fusion and number of levels fused, time to last follow-up, follow-up imaging, date of recurrence, and fusion-related complications. With respect to schwannomatosis, since it represents a new diagnostic entity, it is unknown how many patients included in the present study actually had this diagnosis compared with a diagnosis of sporadic schwannomas. Tumor location was classified by the level of the involved nerve root (cervical, thoracic, or lumbosacral) and anatomical location was classified as intradural, extradural, dumbbell, or paraspinal (tumors originating beyond the neural foramen). Extent of resection was defined as gross total if there was no evidence of residual disease on postoperative MRI and as subtotal if residual tumor was present. The use of intraoperative neuromonitoring was recorded and categorized as somatosensory evoked potentials (SSEPs), motor evoked potentials (MEPs), electromyography (EMG), or evoked EMG. Fusion-related complications were identified through postoperative progress notes, outpatient clinic notes, and postoperative imaging studies including conventional radiographs and CT scans. Complications were classified as follows: new or worsening sensory symptoms (numbness, paresthesias, dysesthesias), new or worsening weakness, wound infection, CSF leak or pseudomeningocele, spinal deformity (defined as any new symptomatic deformity requiring surgical correction), or other.

\section{Statistical Analysis}

Univariate analysis of continuous variables was performed using the Student t-test, and categorical variables were compared using the chi-square or Fisher's exact test. Statistical significance was defined as $\mathrm{p}<0.05$. All analyses were performed with SPSS version 22 (IBM Corp.).

\section{Results \\ Patient Demographics}

A total of 221 tumors in 199 patients were identified. Mean patient age at the time of surgery was 45 years with a range of 1-88 years. Demographics are summarized in Table 1 . There was a slight male predominance with 123 tumors (56\%) in men and 98 tumors (44\%) in women. A clinical diagnosis of NF1 was present in 42 cases (19\%), NF2 in 11 cases (5\%), and absent in 168 cases (76\%). The mean duration of symptoms was 16 months, with pain as the most common presenting symptom (76\%), followed by weakness $(36 \%)$ and sensory changes (34\%). There were 163 schwannomas (74\%), 53 neurofibromas (24\%), and 5 MPNSTs (2\%). Tumors were distributed as follows: 85 cervical (38\%), 62 thoracic (28\%), and 74 lumbosacral (33\%). 
TABLE 1. Summary of patient demographics and tumor characteristics among 221 cases of PNST

\begin{tabular}{|c|c|}
\hline Characteristic & Value \\
\hline \multicolumn{2}{|l|}{ Age at surgery in yrs } \\
\hline Mean & 45 \\
\hline Median & 46 \\
\hline Range & $1-88$ \\
\hline \multicolumn{2}{|l|}{ No. of cases } \\
\hline Male & $123(56 \%)$ \\
\hline Female & $98(44 \%)$ \\
\hline \multicolumn{2}{|l|}{ Cases of NF } \\
\hline Type 1 & $42(19 \%)$ \\
\hline Type 2 & $11(5 \%)$ \\
\hline None & $168(76 \%)$ \\
\hline \multicolumn{2}{|l|}{ Symptom duration in mos } \\
\hline Mean & 16 \\
\hline Median & 6 \\
\hline Range & $0-120$ \\
\hline \multicolumn{2}{|l|}{ Clinical presentation } \\
\hline Spinal pain & $168(76 \%)$ \\
\hline Weakness & $79(36 \%)$ \\
\hline Sensory symptoms & $76(34 \%)$ \\
\hline Gait disturbance & $12(5 \%)$ \\
\hline Bowel/bladder incontinence & $12(5 \%)$ \\
\hline Incidental finding & $4(2 \%)$ \\
\hline \multicolumn{2}{|l|}{ Tumor type } \\
\hline Neurofibroma & $53(24 \%)$ \\
\hline Schwannoma & $163(74 \%)$ \\
\hline MPNST & $5(2 \%)$ \\
\hline \multicolumn{2}{|l|}{ Tumor level } \\
\hline Cervical & $85(38 \%)$ \\
\hline Thoracic & $62(28 \%)$ \\
\hline Lumbosacral & $74(33 \%)$ \\
\hline \multicolumn{2}{|l|}{ Tumor location } \\
\hline Intradural & $130(59 \%)$ \\
\hline Extradural & $26(12 \%)$ \\
\hline Dumbbell & $52(24 \%)$ \\
\hline Paraspinal & $13(6 \%)$ \\
\hline \multicolumn{2}{|l|}{ Extent of resection } \\
\hline GTR & $166(75 \%)$ \\
\hline STR & $54(24 \%)$ \\
\hline Biopsy & $1(0.4 \%)$ \\
\hline Surgical complications & $70(32 \%)$ \\
\hline \multicolumn{2}{|l|}{ Follow-up in mos } \\
\hline Mean & 32 \\
\hline Median & 16 \\
\hline Range & $0-162$ \\
\hline
\end{tabular}

Location was intradural in 130 cases (59\%), extradural in 26 cases (12\%), dumbbell in 52 cases (24\%), and paraspinal in 13 cases $(6 \%)$. The majority of lesions $(75 \%)$ were treated with gross-total resection (GTR). The mean followup time was 32 months.

\section{Surgical Complications}

There were 70 complications among the 221 tumors
TABLE 2. Summary of characteristics in PNST cases with or without surgical complications

\begin{tabular}{|c|c|c|c|}
\hline Characteristic & $\begin{array}{c}\text { Surgical } \\
\text { Complications }\end{array}$ & $\begin{array}{c}\text { No } \\
\text { Complications }\end{array}$ & $\begin{array}{c}\mathrm{p} \\
\text { Value }\end{array}$ \\
\hline No. of cases & $70(32 \%)$ & $151(68 \%)$ & \\
\hline \multicolumn{4}{|l|}{ Patient age in yrs } \\
\hline Mean & 42 & 46 & 0.131 \\
\hline Range & $5-88$ & $1-79$ & \\
\hline \multicolumn{4}{|l|}{ Sex of cases } \\
\hline Male & $44(63 \%)$ & $79(52 \%)$ & 0.142 \\
\hline Female & $26(37 \%)$ & $72(48 \%)$ & \\
\hline \multicolumn{4}{|l|}{ Cases of NF } \\
\hline Type 1 & $13(19 \%)$ & $29(19 \%)$ & 0.911 \\
\hline Type 2 & $7(10 \%)$ & $4(3 \%)$ & $0.039 *$ \\
\hline None & $50(71 \%)$ & $118(78 \%)$ & 0.277 \\
\hline \multicolumn{4}{|l|}{ Spinal location } \\
\hline Cervical & $31(44 \%)$ & $54(36 \%)$ & 0.226 \\
\hline Thoracic & $11(16 \%)$ & $51(34 \%)$ & 0.005 \\
\hline Lumbosacral & $28(40 \%)$ & $46(30 \%)$ & 0.162 \\
\hline $\begin{array}{l}\text { Vertebral levels spanned } \\
\text { by tumor }\end{array}$ & 1.2 & 1.2 & 0.993 \\
\hline Max tumor diameter in $\mathrm{cm}$ & 3.3 & 3.8 & 0.346 \\
\hline \multicolumn{4}{|l|}{ Tumor location } \\
\hline Intradural & $34(48 \%)$ & $96(64 \%)$ & 0.035 \\
\hline Extradural & $8(11 \%)$ & $18(12 \%)$ & 0.916 \\
\hline Dumbbell & $25(36 \%)$ & $27(18 \%)$ & 0.004 \\
\hline Paraspinal & $3(4 \%)$ & $10(7 \%)$ & $0.759^{*}$ \\
\hline \multicolumn{4}{|l|}{ Tumor pathology } \\
\hline Neurofibroma & $18(26 \%)$ & $35(23 \%)$ & 0.681 \\
\hline Schwannoma & $50(71 \%)$ & $113(75 \%)$ & 0.592 \\
\hline MPNST & $2(3 \%)$ & $3(2 \%)$ & $0.653^{*}$ \\
\hline \multicolumn{4}{|l|}{ Intraop neuromonitoring } \\
\hline Any modality & $47(67 \%)$ & $104(69 \%)$ & 0.797 \\
\hline MEP & $45(64 \%)$ & $96(64 \%)$ & 0.919 \\
\hline SSEP & $45(64 \%)$ & $99(66 \%)$ & 0.853 \\
\hline EMG & $45(64 \%)$ & $104(69 \%)$ & 0.498 \\
\hline Evoked EMG & $4(6 \%)$ & $13(9 \%)$ & 0.452 \\
\hline \multicolumn{4}{|l|}{ Extent of resection } \\
\hline GTR & $46(66 \%)$ & $120(79 \%)$ & 0.028 \\
\hline STR & $24(34 \%)$ & $30(20 \%)$ & 0.020 \\
\hline Biopsy & $0(0 \%)$ & $1(1 \%)$ & $1.000^{*}$ \\
\hline \multicolumn{4}{|l|}{ Follow-up in mos } \\
\hline Mean & 32 & 31 & 0.835 \\
\hline Range & $0-160$ & $0-163$ & \\
\hline
\end{tabular}

* Fisher's exact test.

for a rate of $32 \%$. The demographics of patients with and without complications are reviewed in Table 2. There was no significant difference in age, sex, or presenting symptoms among patients who developed complications. Neurofibromatosis Type 2 was more common among patients with complications $(10 \%$ vs $2 \%, \mathrm{p}=0.039)$, while $\mathrm{NF} 1$ was not $(19 \%$ vs $19 \%, p=0.911)$. Cervical and lumbosacral tumors had higher rates of complications $(36 \%$ and $38 \%$, respectively) than thoracic lesions $(18 \%, \mathrm{p}=0.021)$. Complication rates among tumor locations were as fol- 
lows: intradural (34 [26\%] of 130), extradural (8 [31\%] of 26), dumbbell (25 [48\%] of 52), and paraspinal (3 [23\%] of 13), a difference that was statistically significant ( $\mathrm{p}=$ 0.033 ). Tumor pathology was not associated with complication rates; however, neurofibromas were associated with a lower rate of GTR. Complications were more common in the subtotal resection (STR) group than in the GTR group (44\% vs $28 \%$ ), although the difference between the 2 groups was not significant ( $\mathrm{p}=0.022)$. Neither the number of vertebral levels spanned by the tumor (1.2 vs 1.2 levels) nor the maximum tumor diameter (3.3 vs $3.8 \mathrm{~cm})$ was associated with complication rates.

Intraoperative neuromonitoring was used in 47 (67\%) of the 70 cases with postoperative complications compared with $104(69 \%)$ of 151 cases without complications ( $\mathrm{p}=$ 0.797). Among the 46 patients with any new or worsening motor or sensory symptom, intraoperative neuromonitoring was used in 35 cases (76\%), compared with 116 (66\%) of 175 cases without new neurological symptoms (p $=0.204$ ). Among the 34 patients with new or worsening sensory symptoms, intraoperative neuromonitoring was used in 27 cases (79\%); among the 12 patients with new or worsening motor deficits, neuromonitoring was used in 8 cases $(67 \%)$. It was not feasible, and is beyond the scope of this paper, to determine whether neuromonitoring prevented postoperative deficits when it was used, because of changes in technique. Microsurgical technique was used in all cases. Surgical adjuncts such as ultrasonic aspirator and laser were used as indicated with no documented impact on individual complications.

Among the 70 complications, the most common were 34 new or worsening sensory symptoms (15\%). Other complications included new or worsening weakness in 12 cases (5\%), CSF leak or pseudomeningocele in 10 cases $(4 \%)$, wound infection (including superficial and deep) in 11 cases $(5 \%)$, and spinal deformity requiring surgical intervention in 5 cases (2\%). Among the 12 cases of new or worsening weakness, 6 were new deficits and 6 represented a worsening of prior symptoms. Six cases involved planned nerve root sacrifice with expected postoperative deficits. Ten of the 12 cases involved weakness in a nerve root distribution, and 6 of those resulted in only mild deficits without any reported physical impairment. Two patients developed worsening bilateral lower-extremity weakness after surgery. One case occurred in a patient with multiple schwannomas from T-12 to L-3 who had presented with lower-extremity weakness and underwent tumor debulking for spinal cord compression. The second case was a patient with a large cervical schwannoma and intramedullary hemorrhage who had presented with weakness and myelopathy and underwent debulking for alleviation of spinal cord compression. Among the $10 \mathrm{CSF}$ leaks or pseudomeningoceles, 8 were symptomatic with 5 of those requiring surgical repair; 2 cases were asymptomatic but nonetheless required surgical repair. Less common complications included 2 spinal epidural hematomas requiring a return to the operating room, 1 nonoperative cranial subdural hematoma, 1 DVT, 1 case of urinary retention, and 1 recurrent laryngeal nerve injury. Complications are summarized in Table 3.

Among the 221 tumors, only 5 cases were associated
TABLE 3. Summary of surgical complications among 221 cases of PNST

\begin{tabular}{lc}
\hline \multicolumn{1}{c}{ Complication } & No. (\%) \\
\hline New/worsening sensory symptom & $34(15)$ \\
\hline New/worsening weakness & $12(5)$ \\
\hline CSF leak/pseudomeningocele & $10(4)$ \\
\hline Wound infection & $11(5)$ \\
\hline Spinal deformity & $5(2)$ \\
\hline Other & $6(3)$ \\
\hline
\end{tabular}

with new spinal deformity. Four of these cases occurred in pediatric patients with NF1 who underwent multilevel cervical laminectomies for resection of neurofibromas without associated fusion procedures. Kyphotic deformities developed in each case, requiring return to the operating room for spinal fusion. One patient who underwent a spinal fusion with initial tumor resection developed a new spinal deformity. He had initially presented with a giant extradural schwannoma with paraspinal extension causing vena cava compression. He underwent L3-4 laminectomies with an L-3 pedicle subtraction osteotomy and L2-S1 instrumented posterior spinal fusion with pelvic fixation, followed by L2-4 anterior spinal fusion with partial L-3 corpectomy and interbody cage placement. He presented 2 years later with worsening back pain and right lower-extremity weakness. Imaging revealed proximal junctional kyphosis at L1-2 with an associated disc herniation causing severe canal stenosis. He underwent L1-2 laminectomies with discectomy and extension of his posterior instrumented fusion to T-10. At the last follow-up 53 months from his initial surgery, the patient was doing well with normal neurological function.

\section{Tumor Pathology and Complications}

Complications among the different tumor pathologies were compared (Table 4). Among 53 neurofibromas, there were 18 complications (34\%) compared with 50 complications among 163 schwannomas (31\%) and 2 complications among 5 MPNSTs (40\%), differences that were not significant $(\mathrm{p}=0.834)$. The rate of new or worsening sensory symptoms (21\%) and motor deficits (8\%) was slightly higher among neurofibromas than schwannomas $(13 \%$ and $5 \%$, respectively) or MPNSTs (20\% and $0 \%$, respectively); however, these differences were not significant $(p=0.427$ and 0.658 , respectively). Cerebrospinal fluid leaks or pseudomeningoceles $(6 \%)$ and wound infections (7\%) were more common among schwannomas than neurofibromas ( $2 \%$ and $0 \%$, respectively) or MPNSTs $(0 \%$ and $0 \%$, respectively); again, however, these differences were not significant ( $\mathrm{p}=0.408$ and 0.128 , respectively). There was a higher rate of spinal deformity in the neurofibroma group $(8 \%)$ than in the schwannoma $(0.1 \%)$ or MPNST $(0 \%)$ groups, and this difference was significant $(\mathrm{p}=0.012)$.

\section{Tumor Location and Complications}

Complications after surgery for tumors in the cervical, thoracic, and lumbosacral spine were compared (Table 5). 
TABLE 4. Summary of characteristics among 221 PNST cases, according to tumor type

\begin{tabular}{|c|c|c|c|c|}
\hline Characteristic & Neurofibroma & Schwannoma & MPNST & $p$ Value \\
\hline No. of tumors & 53 & 163 & 5 & \\
\hline Mean patient age in yrs & 36 & 48 & 42 & $<0.001$ \\
\hline \multicolumn{5}{|l|}{ NF } \\
\hline Type 1 & $39(74 \%)$ & $2(1 \%)$ & $1(20 \%)$ & $<0.001$ \\
\hline Type 2 & $1(2 \%)$ & $10(6 \%)$ & $0(0 \%)$ & 0.408 \\
\hline None & $13(24 \%)$ & $151(93 \%)$ & $4(80 \%)$ & $<0.001$ \\
\hline \multicolumn{5}{|l|}{ Location } \\
\hline Cervical & $39(74 \%)$ & $44(27 \%)$ & $2(40 \%)$ & $<0.001$ \\
\hline Thoracic & $7(13 \%)$ & $55(34 \%)$ & $0(0 \%)$ & 0.006 \\
\hline Lumbosacral & $7(13 \%)$ & $64(39 \%)$ & $3(60 \%)$ & 0.001 \\
\hline \multicolumn{5}{|l|}{ Dural location } \\
\hline Intradural & $27(51 \%)$ & $102(62 \%)$ & $1(20 \%)$ & 0.067 \\
\hline Extradural & $6(11 \%)$ & $20(12 \%)$ & $0(0 \%)$ & 0.699 \\
\hline Dumbbell & $15(28 \%)$ & $33(20 \%)$ & $4(80 \%)$ & 0.005 \\
\hline Paraspinal & $5(9 \%)$ & $8(5 \%)$ & $0(0 \%)$ & 0.407 \\
\hline \multicolumn{5}{|l|}{ Extent of resection } \\
\hline GTR & $27(51 \%)$ & $135(83 \%)$ & $4(80 \%)$ & $<0.001$ \\
\hline STR & $26(49 \%)$ & $27(16 \%)$ & $1(20 \%)$ & $<0.001$ \\
\hline Biopsy & $0(0 \%)$ & $1(1 \%)$ & $0(0 \%)$ & 0.836 \\
\hline Cases w/ surgical complications & $18(34 \%)$ & $50(31 \%)$ & $2(40 \%)$ & 0.834 \\
\hline \multicolumn{5}{|l|}{ Complication type } \\
\hline New/worse sensory symptom & $11(21 \%)$ & $22(13 \%)$ & $1(20 \%)$ & 0.427 \\
\hline New/worse motor deficit & $4(8 \%)$ & $8(5 \%)$ & $0(0 \%)$ & 0.658 \\
\hline CSF leak/pseudomeningocele & $1(2 \%)$ & $9(6 \%)$ & $0(0 \%)$ & 0.481 \\
\hline Wound infection & $0(0 \%)$ & $11(7 \%)$ & $0(0 \%)$ & 0.128 \\
\hline Spinal deformity & $4(8 \%)$ & $1(1 \%)$ & $0(0 \%)$ & 0.012 \\
\hline Other & $0(0 \%)$ & $4(2 \%)$ & $2(40 \%)$ & $<0.001$ \\
\hline
\end{tabular}

There were 85 cervical, 62 thoracic, and 74 lumbosacral lesions with no significant differences in age or sex. Neurofibromatosis Type 1 was present in 31 cases of cervical tumors (36\%) compared with 6 thoracic $(10 \%)$ and 5 lumbosacral $(7 \%)$ cases, a significant difference $(\mathrm{p}<0.001)$. Cervical tumors were associated with lower rates of pain at presentation (64\%) than the rates associated with thoracic $(82 \%)$ and lumbosacral $(85 \%)$ lesions $(\mathrm{p}=0.006)$. Complications were identified in 31 cervical (36\%), 11 thoracic (18\%), and 28 (38\%) lumbosacral tumors, which was a significant difference $(\mathrm{p}=0.021)$. There were no significant differences in sensory or motor deficits among tumor locations. Cerebrospinal fluid leaks or pseudomeningoceles $(8 \%)$ and wound infections $(8 \%)$ were more common among lumbosacral tumors than cervical $(4 \%$ and $2 \%$, respectively) and thoracic (2\% and 5\%, respectively) tumors; however, these differences were not significant ( $\mathrm{p}$ $=0.164$ and 0.250 , respectively). Rates of deformity were higher among cervical lesions (6\%) than those among thoracic and lumbosacral lesions ( 0 and $1 \%$, respectively, $\mathrm{p}=$ $0.065)$.

Potential associations between surgical complications and intradural, dumbbell, extradural, and paraspinal locations were explored and are summarized in Table 6. Dumbbell tumors were associated with the highest rate of complications (48\%) compared with intradural (26\%), extradural (31\%), and paraspinal (23\%) tumors, a difference that was significant $(\mathrm{p}=0.033)$. There was no statistically significant difference when comparing the type of complication and tumor location, but new or worsening motor deficits were higher among dumbbell tumors (6 [12\%] of 52 ) compared with intradural (4 [3\%] of 130), extradural (1 [4\%] of 26), and paraspinal (1 [8\%] of 13) lesions. The rate of GTR was also notably lower for dumbbell tumors (60\%) compared with intradural (79\%), extradural (85\%), and paraspinal (77\%) tumors, a difference that was significant $(p=0.027)$. Cerebrospinal fluid leaks, pseudomeningoceles, and wound infections were only present among intradural and dumbbell tumors.

\section{Extent of Resection and Complications}

Rates of surgical complications were compared between patients who underwent GTR and those who underwent STR (Table 7). There were 166 patients in the GTR group and 54 in the STR group, with those in the former having a slightly older age (46 vs 41 years, $p=0.031$ ) and those in the latter having a higher rate of NF1 $(46 \%$ vs $10 \%, \mathrm{p}<0.001)$. Rates of NF2 were similar between the groups. Among the subtotally resected tumors, there were a higher rate of cervical lesions and lower rates of thoracic and lumbosacral lesions compared with rates among the gross totally resection lesions. Tumors in the STR group were also more likely to be neurofibromas and possess a dumbbell morphology compared with the GTR group. Tumors in the STR group were larger with a maximum di- 
TABLE 5. Summary of characteristics among 221 PNSTs, according to spinal level

\begin{tabular}{|c|c|c|c|c|}
\hline Characteristic & Cervical & Thoracic & Lumbosacral & $p$ Value \\
\hline No. of tumors & 85 & 62 & 74 & \\
\hline Mean patient age in yrs & 42 & 46 & 48 & 0.099 \\
\hline \multicolumn{5}{|l|}{ Neurofibromatosis } \\
\hline Type 1 & $31(36 \%)$ & $6(10 \%)$ & $5(7 \%)$ & $<0.001$ \\
\hline Type 2 & $5(6 \%)$ & $1(2 \%)$ & $5(7 \%)$ & 0.345 \\
\hline None & $49(58 \%)$ & $55(89 \%)$ & $64(86 \%)$ & $<0.001$ \\
\hline \multicolumn{5}{|l|}{ Tumor pathology } \\
\hline Neurofibroma & $39(46 \%)$ & $7(11 \%)$ & $7(9 \%)$ & $<0.001$ \\
\hline Schwannoma & $44(52 \%)$ & $55(89 \%)$ & $64(86 \%)$ & $<0.001$ \\
\hline MPNST & $2(2 \%)$ & $0(0 \%)$ & $3(4 \%)$ & 0.285 \\
\hline \multicolumn{5}{|l|}{ Dural location } \\
\hline Intradural & $49(58 \%)$ & $32(52 \%)$ & $49(66 \%)$ & 0.218 \\
\hline Extradural & $7(8 \%)$ & $9(14 \%)$ & $10(14 \%)$ & 0.430 \\
\hline Dumbbell & $24(28 \%)$ & $16(26 \%)$ & $12(16 \%)$ & 0.180 \\
\hline Paraspinal & $5(6 \%)$ & $5(8 \%)$ & $3(4 \%)$ & 0.613 \\
\hline \multicolumn{5}{|l|}{ Extent of resection } \\
\hline GTR & $47(55 \%)$ & $56(90 \%)$ & $63(85 \%)$ & $<0.001$ \\
\hline STR & $38(45 \%)$ & $6(10 \%)$ & $10(14 \%)$ & $<0.001$ \\
\hline Biopsy & $0(0 \%)$ & $0(0 \%)$ & $1(1 \%)$ & 0.369 \\
\hline Cases w/ surgical complications & $31(36 \%)$ & $11(18 \%)$ & $28(38 \%)$ & 0.021 \\
\hline \multicolumn{5}{|l|}{ Complication type } \\
\hline New/worse sensory symptom & $14(16 \%)$ & $8(13 \%)$ & $12(16 \%)$ & 0.815 \\
\hline New/worse motor deficit & $5(6 \%)$ & $1(2 \%)$ & $6(8 \%)$ & 0.243 \\
\hline CSF leak/pseudomeningocele & $3(4 \%)$ & $1(2 \%)$ & $6(8 \%)$ & 0.164 \\
\hline Symptomatic & $3(4 \%)$ & $1(2 \%)$ & $4(5 \%)$ & 0.498 \\
\hline Requiring surgical repair & $1(1 \%)$ & $1(2 \%)$ & $5(7 \%)$ & 0.096 \\
\hline Wound infection & $2(2 \%)$ & $3(5 \%)$ & $6(8 \%)$ & 0.250 \\
\hline Spinal deformity & $5(6 \%)$ & $0(0 \%)$ & $1(1 \%)$ & 0.065 \\
\hline Other & $3(4 \%)$ & $0(0 \%)$ & $3(4 \%)$ & 0.294 \\
\hline
\end{tabular}

ameter of $4.4 \mathrm{~cm}$ compared with $3.3 \mathrm{~cm}$ in the GTR group; however, this difference was not statistically significant ( $\mathrm{p}$ $=0.072$ ).

There were 24 complications in the STR group (44\%) compared with $46(28 \%)$ in the GTR group $(\mathrm{p}=0.022)$. Rates of new or worsening sensory symptoms were $15 \%$ in the GTR group and $17 \%$ in the STR group $(p=0.777)$. Rates of new or worsening weakness were similar in the STR and GTR groups (7\% vs 5\%, respectively). There were no significant differences in the rates of CSF leak or pseudomeningocele, wound infection, or postoperative spinal deformity between the 2 groups. It was not possible to determine retrospectively if the use of neuromonitoring influenced whether GTR or STR was accomplished; however, the rate of GTR among cases with neuromonitoring was $79 \%$ compared with $66 \%$ in those without $(p=0.022)$. This difference remained significant for different modalities including MEPs, SSEPs, and EMG.

\section{Discussion}

The goal of this study was to describe outcomes in spinal nerve sheath tumor surgery and identify factors associated with new or worsening postoperative neurological deficits and surgical complications. Among the 221 tumors included in this study, there were 70 complications for a rate of $32 \%$. We included new or worsening neurological deficits (motor and sensory) as complications even in cases in which they were expected given the need for nerve root sacrifice. Overall, the rate of new or worsening sensory symptoms was $15 \%$; the rate of new or worsening weakness was $5 \%$. Kim et al. examined their experience in the management of spinal schwannomas more than 20 years ago and found that among 31 patients who had undergone nerve sacrifice, 7 (22\%) developed partial loss of strength or sensation, though none was debilitating. ${ }^{15}$ Preoperative EMG was performed in a subset of these patients and showed that denervation was associated with an increased risk of postoperative deficit. These authors concluded that spinal roots associated with spinal schwannomas were often nonfunctional and that the risk of disabling neurological injury after nerve sacrifice was small.

In subsequent studies, Seppälä and colleagues assessed both neurological outcomes and complications related to wound healing and infection. ${ }^{24}$ Among 142 spinal schwannomas with follow-up, 10 (7\%) were considered clinically worse postoperatively; however, the specific symptoms were not described. Nineteen of the 187 patients in the study suffered complications related to wound infection or dehiscence, bleeding, DVT, or the lungs. In a similar study of 32 spinal neurofibromas, Seppälä et al. reported 5 neurological deteriorations (16\%). ${ }^{23}$ Late complications 
TABLE 6. Summary of characteristics among 221 PNST cases, according to tumor location

\begin{tabular}{|c|c|c|c|c|c|}
\hline Characteristic & Intradural & Dumbbell & Extradural & Paraspinal & p Value \\
\hline No. of tumors & 130 & 52 & 26 & 13 & \\
\hline Mean patient age in yrs & 45 & 45 & 45 & 42 & 0.935 \\
\hline \multicolumn{6}{|l|}{ NF } \\
\hline Type 1 & $22(17 \%)$ & $13(25 \%)$ & $3(12 \%)$ & $4(31 \%)$ & 0.297 \\
\hline Type 2 & $8(6 \%)$ & $2(4 \%)$ & $1(4 \%)$ & $0(0 \%)$ & 0.736 \\
\hline None & $100(77 \%)$ & $37(71 \%)$ & $22(85 \%)$ & $9(69 \%)$ & 0.549 \\
\hline \multicolumn{6}{|l|}{ Tumor pathology } \\
\hline Neurofibroma & $27(21 \%)$ & $15(29 \%)$ & $6(23 \%)$ & $5(38 \%)$ & 0.405 \\
\hline Schwannoma & $102(78 \%)$ & $33(63 \%)$ & $20(77 \%)$ & $8(62 \%)$ & 0.140 \\
\hline MPNST & $1(1 \%)$ & $4(8 \%)$ & $0(0 \%)$ & $0(0 \%)$ & 0.027 \\
\hline \multicolumn{6}{|l|}{ Location } \\
\hline Cervical & $49(38 \%)$ & $24(46 \%)$ & $7(27 \%)$ & $5(38 \%)$ & 0.424 \\
\hline Thoracic & $32(25 \%)$ & $16(31 \%)$ & $9(35 \%)$ & $5(38 \%)$ & 0.531 \\
\hline Lumbosacral & $49(38 \%)$ & $12(23 \%)$ & $10(38 \%)$ & $3(23 \%)$ & 0.214 \\
\hline \multicolumn{6}{|l|}{ Extent of resection } \\
\hline GTR & $103(79 \%)$ & $31(60 \%)$ & $22(85 \%)$ & $10(77 \%)$ & 0.027 \\
\hline STR & $27(21 \%)$ & $21(40 \%)$ & $4(15 \%)$ & $2(15 \%)$ & 0.020 \\
\hline Biopsy & $0(0 \%)$ & $0(0 \%)$ & $0(0 \%)$ & $1(8 \%)$ & $<0.001$ \\
\hline Cases w/ surgical complications & $34(26 \%)$ & $25(48 \%)$ & $8(31 \%)$ & $3(23 \%)$ & 0.033 \\
\hline \multicolumn{6}{|l|}{ Complication type } \\
\hline New/worse sensory symptom & $14(11 \%)$ & $12(23 \%)$ & $6(23 \%)$ & $2(15 \%)$ & 0.129 \\
\hline New/worse motor deficit & $4(3 \%)$ & $6(12 \%)$ & $1(4 \%)$ & $1(8 \%)$ & 0.142 \\
\hline CSF leak/pseudomeningocele & $7(5 \%)$ & $3(6 \%)$ & $0(0 \%)$ & $0(0 \%)$ & 0.521 \\
\hline Symptomatic & $5(4 \%)$ & $3(6 \%)$ & $0(0 \%)$ & $0(0 \%)$ & 0.537 \\
\hline Requiring surgical repair & $7(5 \%)$ & $0(0 \%)$ & $0(0 \%)$ & $0(0 \%)$ & 0.167 \\
\hline Wound infection & $8(6 \%)$ & $3(6 \%)$ & $0(0 \%)$ & $0(0 \%)$ & 0.477 \\
\hline Spinal deformity & $3(2 \%)$ & $1(2 \%)$ & $1(4 \%)$ & $0(0 \%)$ & 0.891 \\
\hline Other & $1(1 \%)$ & $4(8 \%)$ & $0(0 \%)$ & $1(8 \%)$ & 0.034 \\
\hline
\end{tabular}

included spinal deformity in 2 patients and severe dysesthesias in another 2 patients. Among the 15 patients with nerve sacrifice who were alive at the last follow-up, 6 $(40 \%)$ had sensory deficits and 5 (33\%) had motor deficits, all of which were mild. In a more contemporary series, Safavi-Abbasi et al. examined complications in a cohort in which neurophysiological monitoring was used in most cases. $^{22}$ Among 131 cases of schwannoma, 16 (12\%) developed sensory deficits and $3(2 \%)$ had motor weakness. An additional 14 (11\%) had CSF leaks or pseudomeningoceles, 5 (4\%) had wound infections, 4 (3\%) had meningitis, and $1(1 \%)$ had spinal deformity. In other recent studies, Fernandes et al. reported a complication rate of $10 \%$ that included CSF fistula, wound infection, DVT, and pulmonary complication. ${ }^{11}$ Nanda et al. reported 18 complications in 61 patients for a rate of $30 \%$, which included pseudomeningocele and CSF leak in 5 cases $(8 \%)$, instability in 2 cases (3\%), wound infection in 3 cases (5\%), and 1 case each of DVT, pulmonary embolism, incomplete recurrent laryngeal nerve injury, trigeminal nerve injury, and pseudarthrosis. ${ }^{18}$

In the current study we describe neurological outcomes and surgical complications in a series of 221 tumors treated at a single center. There was no difference in age, sex, clinical presentation, symptom duration, or extent of resection among patients when comparing those with new or worsening neurological outcomes and surgical com- plications and those without such outcomes. There was a higher incidence of NF2 in patients with complications, and although this difference was statistically significant, it may be related to the small sample size. There was no difference in complications when comparing different tumor pathologies or sizes; however, spinal level was an important factor since complications were more common among cervical and lumbosacral tumors than among thoracic spine lesions. Not surprisingly, this difference appears to be driven by increased rates of CSF leak, pseudomeningocele, and motor deficits. Rates of new or worsening neurological deficits did not significantly differ by spinal level; however, as expected, rates were lower among thoracic tumors compared with those among cervical or lumbosacral lesions. We observed a higher complication rate among dumbbell tumors; these lesions had the highest rate of new or worsening motor deficits and rates of CSF leak or pseudomeningocele and a wound infection rate that was similar to that for intradural lesions, although none of these differences met statistical significance.

Among 221 tumors, only 5 were associated with new spinal deformity. Four of these were cervical neurofibromas in pediatric patients who had undergone multilevel laminectomies without spinal fusion at the initial surgery. It is therefore appropriate to consider spinal fusion in these patients given their risk. We reported outcomes for patients with spinal nerve sheath tumors who had undergone spinal 
TABLE 7. Summary of characteristics in 221 PNST cases, according to extent of resection

\begin{tabular}{|c|c|c|c|}
\hline Characteristic & GTR & STR & $p$ Value \\
\hline No. of tumors & 166 & 54 & \\
\hline Mean patient age in yrs & 46 & 41 & 0.031 \\
\hline \multicolumn{4}{|l|}{ NF } \\
\hline Type 1 & $17(10 \%)$ & $25(46 \%)$ & $<0.001$ \\
\hline Type 2 & $6(4 \%)$ & $5(9 \%)$ & 0.098 \\
\hline None & $143(86 \%)$ & $24(44 \%)$ & $<0.001$ \\
\hline \multicolumn{4}{|l|}{ Tumor location } \\
\hline Cervical & $47(28 \%)$ & $38(70 \%)$ & $<0.001$ \\
\hline Thoracic & $56(34 \%)$ & $6(11 \%)$ & 0.001 \\
\hline Lumbosacral & $63(38 \%)$ & $10(18 \%)$ & 0.008 \\
\hline \multicolumn{4}{|l|}{ Dural location } \\
\hline Intradural & $103(62 \%)$ & $27(50 \%)$ & 0.118 \\
\hline Extradural & $22(13 \%)$ & $4(7 \%)$ & 0.248 \\
\hline Dumbbell & $31(19 \%)$ & $21(39 \%)$ & 0.002 \\
\hline Paraspinal & $10(6 \%)$ & $2(4 \%)$ & $0.735^{*}$ \\
\hline \multicolumn{4}{|l|}{ Tumor pathology } \\
\hline Neurofibroma & $27(16 \%)$ & $26(48 \%)$ & $<0.001$ \\
\hline Schwannoma & $135(81 \%)$ & $27(50 \%)$ & $<0.001$ \\
\hline MPNST & $4(2 \%)$ & $1(2 \%)$ & $1.000^{*}$ \\
\hline \multicolumn{4}{|l|}{ Tumor size } \\
\hline Max diameter in $\mathrm{cm}$ & 3.3 & 4.4 & 0.072 \\
\hline Vertebral levels spanned & 1.2 & 1.2 & 0.352 \\
\hline Cases w/ surgical complications & $46(28 \%)$ & $24(44 \%)$ & 0.022 \\
\hline \multicolumn{4}{|l|}{ Complication type } \\
\hline New/worse sensory symptom & $25(15 \%)$ & $9(17 \%)$ & 0.777 \\
\hline New/worse motor deficit & $8(5 \%)$ & $4(7 \%)$ & 0.467 \\
\hline CSF leak/pseudomeningocele & $9(5 \%)$ & $1(2 \%)$ & $0.457^{*}$ \\
\hline Wound infection & $7(4 \%)$ & $4(7 \%)$ & $0.470^{*}$ \\
\hline Spinal deformity & $2(1 \%)$ & $3(6 \%)$ & $0.096^{*}$ \\
\hline Other & $4(2 \%)$ & $2(4 \%)$ & $0.637^{*}$ \\
\hline \multicolumn{4}{|l|}{ Intraop neuromonitoring } \\
\hline Any modality & $120(72 \%)$ & $30(56 \%)$ & 0.022 \\
\hline MEP & $112(67 \%)$ & $28(52 \%)$ & 0.038 \\
\hline SSEP & $114(69 \%)$ & $29(54 \%)$ & 0.045 \\
\hline EMG & $119(72 \%)$ & $29(54 \%)$ & 0.014 \\
\hline Evoked EMG & $13(8 \%)$ & $4(7 \%)$ & $1.000^{*}$ \\
\hline
\end{tabular}

* Fisher's exact test.

fusion with tumor resection and found that fusions were most common among dumbbell and extradural tumors as well as tumors at the cervicothoracic junction..$^{21}$ Rates of new or worsening neurological deficit, CSF leak, pseudomeningocele, and infection were no different among patients who underwent fusions compared with those who did not.

The rate of GTR in this series was $75 \%$, which on initial review may seem lower than expected; however, the rate was driven by a high number of cervical neurofibromas in patients with NF1. Among schwannomas, the rate of GTR was $83 \%$ compared with 51\% among neurofibromas. Among 53 neurofibromas included in this analysis, $74 \%$ of cases involved patients with NF1, 74\% were located in the cervical spine, and $79 \%$ were either intradural or dumbbell lesions. The high rate of cervical lesions is probably driven by the fact that these tumors are more likely to be symp- tomatic and treated compared with neurofibromas at other spinal levels. The lower rate of GTR can be explained by the fact that NF1 is not a curable entity and that the goal of surgery in these cases is decompression of the spinal cord and neural elements and not necessarily complete tumor resection.

With respect to the use of intraoperative neuromonitoring, there was no difference in complication rates when comparing cases with and without this adjunct. This finding does not imply that neuromonitoring is not a useful tool in the resection of these lesions, but rather that the likelihood of a postoperative deficit is probably more attributable to the invasive nature of the specific tumor rather than an inability to identify functional nerve roots. Additionally, even in cases with neuromonitoring, tumor resection may inevitably require nerve root sacrifice, thus explaining the similar rates of postoperative motor and sensory deficits. Our overall rates of new or worsening sensory symptoms $(15 \%)$ and new or worsening weakness $(5 \%)$ are consistent with other reports. Interestingly, we found higher rates of intraoperative neuromonitoring use among tumors treated with GTR than among tumors treated with STR. The retrospective nature of this study makes it difficult to determine if the use of neuromonitoring was directly responsible for the higher rates of GTR, and although these findings are intuitive, they warrant future study.

This study is limited by its retrospective design and limited follow-up. The mean time from surgery to the last clinic visit was 32 months; therefore, our rates of new or worsening neurological deficit may actually be overestimates since in some cases neurological function can improve over time. Although we identified a statistically significant increase in surgical complications among patients with NF2, the sample numbers are too small to make any definitive conclusions about the increased risk in these patients, and future studies should investigate this potential relationship. The rarity of these lesions makes prospective analysis challenging, but future studies may also focus on pre- and postoperative imaging features that can predict ease of resection or anticipate intraoperative challenges so that a particular technique can be avoided to prevent postoperative deficits.

\section{Conclusions}

Resection is a safe and effective treatment for spinal nerve sheath tumors. New or worsening neurological deficits or surgical complications were present in $32 \%$ of cases. The most common was new or worsening sensory symptoms (15\%), followed by new or worsening weakness (5\%), CSF leak or pseudomeningocele (5\%), wound infection (5\%), and spinal deformity (2\%). Complications were more common in cervical and lumbosacral tumors but had no association with patient age, clinical presentation, symptom duration, tumor size, or tumor pathology. Intradural and dumbbell tumors were associated with higher rates of CSF leak, pseudomeningocele, and wound infection. Use of intraoperative neuromonitoring was associated with a higher rate of GTR; however, determining the true effect of neuromonitoring in minimizing postoperative neuro- 
logical deficits and enhancing the extent of resection was not feasible given the retrospective nature of this study. Although undesirable, neurological deficits and surgical complications represent an inevitable consequence of spinal nerve sheath tumor surgery given the intimacy of these lesions with functional neural elements.

\section{References}

1. Abul-Kasim K, Thurnher MM, McKeever P, Sundgren PC: Intradural spinal tumors: current classification and MRI features. Neuroradiology 50:301-314, 2008

2. Aghayev K, Vrionis F, Chamberlain MC: Adult intradural primary spinal cord tumors. J Natl Compr Canc Netw 9:434-447, 2011

3. Albanese V, Platania N: Spinal intradural extramedullary tumors. Personal experience. J Neurosurg Sci 46:18-24, 2002

4. Antinheimo J, Sankila R, Carpén O, Pukkala E, Sainio M, Jääskeläinen J: Population-based analysis of sporadic and type 2 neurofibromatosis-associated meningiomas and schwannomas. Neurology 54:71-76, 2000

5. Carey JC, Viskochil DH: Neurofibromatosis type 1: A model condition for the study of the molecular basis of variable expressivity in human disorders. Am J Med Genet 89:7-13, 1999

6. Celli P: Treatment of relevant nerve roots involved in nerve sheath tumors: removal or preservation? Neurosurgery 51:684-692, 2002

7. Chamberlain MC, Tredway TL: Adult primary intradural spinal cord tumors: a review. Curr Neurol Neurosci Rep 11:320-328, 2011

8. Conti P, Pansini G, Mouchaty H, Capuano C, Conti R: Spinal neurinomas: retrospective analysis and long-term outcome of 179 consecutively operated cases and review of the literature. Surg Neurol 61:34-44, 2004

9. Egelhoff JC, Bates DJ, Ross JS, Rothner AD, Cohen BH: Spinal MR findings in neurofibromatosis types 1 and 2. AJNR Am J Neuroradiol 13:1071-1077, 1992

10. Engelhard HH, Villano JL, Porter KR, Stewart AK, Barua M, Barker FG, et al: Clinical presentation, histology, and treatment in 430 patients with primary tumors of the spinal cord, spinal meninges, or cauda equina. J Neurosurg Spine 13:67-77, 2010

11. Fernandes RL, Lynch JC, Welling L, Gonçalves M, Tragante $\mathrm{R}$, Temponi V, et al: Complete removal of the spinal nerve sheath tumors. Surgical technics and results from a series of 30 patients. Arq Neuropsiquiatr 72:312-317, 2014

12. Huson SM, Harper PS, Compston DA: Von Recklinghausen neurofibromatosis. A clinical and population study in southeast Wales. Brain 111:1355-1381, 1988

13. Jeon JH, Hwang HS, Jeong JH, Park SH, Moon JG, Kim CH: Spinal schwannoma; analysis of 40 cases. J Korean Neurosurg Soc 43:135-138, 2008

14. Jinnai T, Koyama T: Clinical characteristics of spinal nerve sheath tumors: analysis of 149 cases. Neurosurgery 56:510 515,2005

15. Kim P, Ebersold MJ, Onofrio BM, Quast LM: Surgery of spinal nerve schwannoma. Risk of neurological deficit after resection of involved root. J Neurosurg 71:810-814, 1989

16. Klekamp J, Samii M: Surgery of Spinal Tumors. New York: Springer, 2007

17. Koontz NA, Wiens AL, Agarwal A, Hingtgen CM, Emerson RE, Mosier KM: Schwannomatosis: the overlooked neurofibromatosis? AJR Am J Roentgenol 200:W646-W653, 2013

18. Nanda A, Kukreja S, Ambekar S, Bollam P, Sin AH: Surgical strategies in the management of spinal nerve sheath tumors. World Neurosurg 83:886-899, 2015

19. Poyhonen M, Leisti EL, Kytölä S, Leisti J: Hereditary spi- nal neurofibromatosis: a rare form of NF1? J Med Genet 34:184-187, 1997

20. Riccardi VM: Neurofibromatosis: Phenotype, Natural History, and Pathogenesis, ed 2. Baltimore: Johns Hopkins University Press, 1992

21. Safaee M, Oh T, Barbaro NM, Chou D, Mummaneni PV, Weinstein PR, et al: Results of spinal fusion after spinal nerve sheath tumor resection. World Neurosurg 90:6-13, 2016

22. Safavi-Abbasi S, Senoglu M, Theodore N, Workman RK, Gharabaghi A, Feiz-Erfan I, et al: Microsurgical management of spinal schwannomas: evaluation of 128 cases. J Neurosurg Spine 9:40-47, 2008

23. Seppälä MT, Haltia MJ, Sankila RJ, Jääskeläinen JE, Heiskanen O: Long-term outcome after removal of spinal neurofibroma. J Neurosurg 82:572-577, 1995

24. Seppälä MT, Haltia MJ, Sankila RJ, Jääskeläinen JE, Heiskanen O: Long-term outcome after removal of spinal schwannoma: a clinicopathological study of 187 cases. J Neurosurg 83:621-626, 1995

25. Stadler JA III, Qadri U, Tang JA, Scheer JK, Melkonian SC, Smith ZA, et al: Malignant peripheral nerve sheath tumors of the spine: a SEER database analysis. J Clin Neurosci 21:1106-1111, 2014

26. Thakkar SD, Feigen U, Mautner VF: Spinal tumours in neurofibromatosis type 1: an MRI study of frequency, multiplicity and variety. Neuroradiology 41:625-629, 1999

27. Tonsgard JH, Kwak SM, Short MP, Dachman AH: CT imaging in adults with neurofibromatosis-1: frequent asymptomatic plexiform lesions. Neurology 50:1755-1760, 1998

28. Viskochil D, Carey JC: Alternate and related forms of the neurofibromatoses, in Huson SM, Hughes RAC (eds): The Neurofibromatoses: A Pathogenetic and Clinical Overview. London: Chapman and Hall Medical, 1994

29. von Deimling A, Krone W, Menon AG: Neurofibromatosis type 1: pathology, clinical features and molecular genetics. Brain Pathol 5:153-162, 1995

30. Wimmer K, Mühlbauer M, Eckart M, Callens T, Rehder H, Birkner T, et al: A patient severely affected by spinal neurofibromas carries a recurrent splice site mutation in the NF1 gene. Eur J Hum Genet 10:334-338, 2002

\section{Disclosures}

Dr. Ames is a consultant for DePuy, Stryker, Medtronic; owns stock in Doctors Research Group; holds a patent with Fish \& Richardson, PC; and receives royalties from Biomet Spine and Stryker. Dr. Chou is a consultant for Globus, Medtronic, and Orthofix. Dr. Mummaneni is a consultant for DePuy Spine; owns stock in Spinicity/ISD; receives royalties from Thieme Publishing, DePuy Spine, Springer Publishing, and Taylor and Francis Publishing; receives honoraria from Globus and AOSpine; and receives funding from the NREF.

\section{Author Contributions}

Conception and design: Safaee, Ames. Acquisition of data: Safaee, Lyon, Chin, Tihan, Ames. Analysis and interpretation of data: all authors. Drafting the article: Safaee, Ames. Critically revising the article: Safaee, Lyon, Barbaro, Chou, Mummaneni, Weinstein, Tihan, Ames. Reviewed submitted version of manuscript: Safaee, Ames. Approved the final version of the manuscript on behalf of all authors: Safaee. Administrative/ technical/material support: Ames. Study supervision: Ames.

\section{Correspondence}

Michael Safaee, Department of Neurological Surgery, 505 Parnassus Ave., Rm. M779, San Francisco, CA 94143. email: michael.safaee@ucsf.edu. 